the splitting off of the phosphate of phosphoglyceric acid and the consequent formation of pyruvic acid proceed undisturbed. The pyruvic acid cannot, however, react with the glycerophosphoric acid, so that here no lactic acid formation takes place.

These results could also be explained in another way. The triose phosphoric acid appearing as an intermediate during the reaction between pyruvic acid and glycero-phosphoric acid might itself be resynthesised to hexose di-phosphoric acid which then decomposes into an oxidised and a reduced half. This interpretation, that the splitting of the carbon-carbon bond at the $3: 4$ position is at the same time an oxidation-reduction process, certainly has its merits. However, the behaviour of glyceric aldehyde phosphoric acid lends support to the supposition of a previous decomposition to triose phosphoric acid. H. O. L. Fischer, the son of Emil Fischer, succeeded not long ago in synthesising glyceric aldehyde phosphoric acid. Smythe and Gerischer, working in $O$. Warburg's institute, showed that the dextro-rotary component of this racemic compound is easily fermented and Embden has observed abundant formation of lactic acid on addition of glyceric aldehyde phosphoric acid to muscle tissue.

Thanks to the courtesy of Dr. Fischer, I was able to study the appearance of intermediate products in muscle extract during the reactions of this substance. Actually, exactly one half, that is one optical component, was transformed into phosphoglyceric acid and glycero-phosphoric acid. In the muscle extract with added sulphite, but without fluoride, pyruvic acid and glycero-phosphoric acid were formed. The glyceric aldehyde phosphoric acid thus behaves exactly as does the intermediary product. This is thus the first synthetic ester that is converted into lactic acid as easily and by the same path as the biological esters.

$$
{ }^{2} \text { Biochem. Z., 222, 337, Fig. 8; } 1930 .
$$

(To be continued.)

\title{
Ionospheric Investigations in High Latitudes
}

\section{By Prof. E. V. Appleton, F.R.S., R. Naismitir and G. Builder}

$\mathrm{I}^{\mathrm{N}}$ connexion with the International Polar Year $1932-33$, a series of wireless observations has been made at Tromsø (lat. $69^{\circ} 39 \cdot 8^{\prime} \mathrm{N}$.; long. $18^{\circ} 56 \cdot 9^{\prime}$ E.) in Norway. The fundamental aim of the work may be briefly stated to be the investigation of ionospheric conditions in high latitudes and of the relation between these conditions and magnetic and auroral disturbance. The observations may be regarded as an extension of the work previously conducted on similar lines in south-east England by British workers under the auspices of the Radio Research Board of the Department of Scientific and Industrial Research. The expedition to Norway for the thirteen months of the International Polar Year has been sent out by that Department and contributions towards the total cost have been made by the British National Committee for the Second Polar Year and by the Council of the Institution of Electrical Engineers.

Special facilities and privileges have been accorded to the expedition by the Norwegian Government and by the Norwegian Committee for Cosmic Physics, while the latter body invited us to make our principal receiving station at the Auroral Observatory, Trcmsø, where laboratory and living accommodation has been provided. The sending station was erected at Simavik, about $20 \mathrm{~km}$. north of Tromsø, on the island of Ringvascoy. The choice of these sites and many other helpful arrangements were made for us by $\mathrm{Mr}$. R. A. Watson Watt, who visited Troms in March, 1932. It has proved a great advantage to have the receiving site at the Observatory at Tromsø, where the magnetic records have been immediately available and where Director Harang and Mr. E. Tønsberg have given us every other possible assistance. A member of our party, Mr. W. C. Brown, has been in charge of the sending station at Simavik during the whole period of the observations.

The expedition arrived in Tromsø on July 15, 1932, and the sending and recciving stations were erected and in working order by July 22 . Observations according to the programme prepared by the Polar Year Sub-Committce of the Union Radio Scientifique Internationale and in accordance with a special British programme have been carried out since the beginning of August 1932, while corresponding measurements for purposes of comparison have been made in south-east England. A full account of the results obtained must naturally await the completion of the remainder of the series of observations and the full reduction of the data ; but since the beginning of the work certain results have been immediately apparent and their continued confirmation prompts this interim statement.

Before proceeding to summarise some of the salient results obtained, it may perhaps be useful to mention the kind of problem which it was hoped would be solved by a comparison of ionospheric measurements in high and temperate latitudes. If ultra-violet light is the ionising agency for either of the two main reflecting regions in the upper atmosphere, we should expect that region to be more strongly ionised by day than by night, and also to be of lower electrical content at Tromsø than in south-east England. On the other hand, if charged particles, entering the earth's atmo. sphere from outside, constitute the ionising agency, the influence of the earth's magnetic field is such that these particles should be expected to con. verge near the magnetic poles and also to impinge on the dark side of the earth. In this case it will readily be seen that their effects should be radically different from those produced by ultra-violet 
light. On the immediately practical side, it was hoped that the investigations would perhaps also elucidate the special difficulties which occur in effecting communication in circumstances in which the wireless ray traverses the polar caps.

The results summarised below bear directly on both these matters.

(a) General. In the first place, it may be stated that the prosecution of ionospheric investigation in a region so liable to magnetic disturbance as Tromsø has emphasised the importance of the result, previously found from measurements of ionisation in England, that an increase in ionisation, as measured by radio methods, is very frequently found to occur with a magnetic storm. In high latitudes, however, the correlation is very much more marked because the magnetic disturbances themselves and the corresponding increases of ionisation are of very much greater magnitude. So far as wireless observations are concerned, the distinction between results on magnetically quiet and magnetically disturbed days is therefore a vital one.

(b) The Upper and Lower Reflecting Regions in Tromsø. For undisturbed conditions there are usually the two reffecting regions which have been observed in England. We shall refer to them as the upper and lower reflecting regions. Regarding 'normality' as the behaviour exhibited by the corresponding regions over south-east England, then we can say that the upper region at Troms $\varnothing$ is the more normal of the two. In this connexion it will be remembered that the lower region is at approximately the same height as the most frequent auroræ.

(c) Undisturbed Conditions. For undisturbed conditions it is quite clear that the daily maximum ionisation content for both upper and lower regions is less at Tromsø than that in south-east England. We find, on the other hand, that the seasonal variation of normal ionisation is greater in high than in temperate latitudes. As an example of the order of magnitude of the ratio of maximum noon ionisation in Tromsø to that in England, we may quote the equinox value of 60-70 per cent. This ratio is, we imagine, of the order which could be predicted from Prof. S. Chapman's theory of atmospheric ionisation by monochromatic radiation, and suggests very strongly that the ordinary undisturbed ionisation value is that caused by ultra-violet light from the sun. For undisturbed conditions the normal diurnal variation, with the usual sunrise and sunset correlation, is always evident with the upper region.

(d) Disturbed Conditions. One of the most remarkable features of the results has been the frequent occurrence of disturbed conditions. This is particularly the case with the lower region. In contrast with England, the greatest ionisation densities measured for this region are encountered not at noon, but during the night (usually from $20.00 \mathrm{hr}$. onwards). In fact, it may be said-using the very special sense of 'normal' adopted abovethat this region is more frequently 'abnormal' than 'normal'. Now the magnetic records at Tromsø show just the same frequency of abnormality. An evening without some kind of magnetic disturbance is exceptional, and such disturbances usually last from 20.00 to 04.00 (or sometimes from $16 \cdot 00$ to $04 \cdot 00$ ) local time. The correlation between disturbed magnetic conditions and abnormal ionisation is very close indeed; a small disturbance during the night will be accompanied by an increase in lower region ionisation (this is specially noticeable when the general magnetic activity is low) while during conditions of intense magnetic activity we find a complete cessation of echoes on all of the available wave-lengths (from 500 metres to 20 metres) normally in use for the observations. The same complete absence of reflection is found during the daytime both during and for some time after magnetic activity. This absence of echoes on all wave-lengths, which we have previously encountered in our work in temperate latitudes on only one occasion, cannot be due to electron-limitation, for the conditions for this could not occur so suddenly as does the disappearance of the echoes. Moreover, we have frequently been able to follow the increase of nocturnal ionisation during the progress of an individual storm. The absence of echoes must therefore be caused by absorption-limitation due to the production of ionisation at abnormally low levels. We must, in fact, conclude that the ionising agency which causes magnetic storms can produce ionisation at levels very definitely below that at which we can detect ionisation produced by ultra-violet light. This result is of special interest in connexion with Director Harang and Dr. Bauer's measurements of occasional auroræ extending 20-30 kilometres below the level to which normal auroræ penetrate.

Another striking feature of the ionospheric conditions is the violent fading and complexity of echoes which accompany the onset of a magnetic disturbance.

Our results as a whole, therefore, show that to account for wireless phenomena in high latitudes we must take into account both the normal influence of ultra-violet light and the abnormal influence of ionising charged particles. The ionising charged particles produce electrification in and below the normal lower region. The fact that the ionisation is found to occur on the dark side of the earth is explicable on the theory of Birkeland as developed by Størmer. The absorption which occurs during the day is probably due to ionisation caused by particles which are initially uncharged but acquire a charge in the early stages of their journey through the atmosphere. Our observations suggest that such particles are, in general, more penetrating than those which impinge on the dark side of the earth. The practical difficulty of maintaining communication over the polar cap can doubtless be traced to the frequent absence of reflection from the ionosphere which we have found to be so closely associated with conditions of magnetic activity. 